\title{
Current trends of HIVIAIDS in Asia
}

\author{
Adekunle Sanyaolu ${ }^{1}$, Chuku Okorie ${ }^{2}$, Anjali Kumar ${ }^{3}$,Deja LaMoure ${ }^{4}$, Mourad Rabadi ${ }^{5}$, Jennings \\ Hernandez ${ }^{6}$, George Omiloli ${ }^{7}$
}

${ }^{1}$ Consultant, Federal Ministry of Health, Abuja, Nigeria. ${ }^{2}$ Adjunct Faculty, Essex County College, Newark, New Jersey, USA. ${ }^{3,4,5,7}$ Medical Student, Saint James School of Medicine, Anguilla, British West Indies.

\begin{abstract}
It is very important to recognize the trends in HIV/AIDS in specific areas such as Asia because it is vital to understanding the effectiveness of current approaches towards diagnosis and treatment. It is also very important to understand the risk factors that greatly predispose people in Asia to contracting HIV/AIDS such as lifestyle, culture, and religion. This review extensively analyzes the current trends of HIV/AIDS in India, China, Thailand, Cambodia and Indonesia. Additionally, cultural diversity carries certain social and religious stigmas associated with the disease. These social stigmas also pose as a significant influence on government involvement with regards to the funding of HIV/AIDS awareness, education, prevention, and the protection of human rights. Lack of education about the methods that help people from the disease and mode of transmission remains a significant hindrance in the prevention of a further rise in epidemiological statistics. Moreover, these factors are attributed to the rising incidence or risk of HIV within several populations amongst these countries. This review also analyzes the clinical presentation, epidemiological statistics, and the financial and socioeconomic impacts of HIV/AIDS in India, China, Thailand, Cambodia and Indonesia. Financial burdens and lack of government infrastructure in the healthcare systems are largely responsible for the rapidly rising prevalence of the disease among these populations, along with the inaccessibility to prevention and treatment methods. Furthermore, the scarcity of available antiretroviral and preventative medications is discussed. Lastly, this review explores various methods of diagnosis, treatment and prevention plans that are implemented in modern medicine with respect to HIV/AIDS.
\end{abstract}

Keywords: HIV/AIDS, Trends, CD4 cells, Highly Active Antiretroviral Therapy (HAART), Asia.

\section{Introduction}

Human Immunodeficiency Virus (HIV) is a Lentivirus and the causative agent of the acquired immune deficiency syndrome. It causes progressive failure of the body's immune system rendering it susceptible to infections and neoplasms. Anti-retroviral drugs are required to stop the progression of HIV to Acquired Immunodeficiency Syndrome (AIDS) but patients are not cured since medication is required permanently. 1,2

It is very important to recognize trends in HIV/AIDS in specific areas such as Asia because it is vital to understanding the effectiveness of current approaches towards diagnosis and treatment. ${ }^{3}$ Thus, knowing the statistics such as incidence, prevalence, rates of survival, and 5-year survival rate are important but does not give a detailed picture in drawing conclusions about trends, hence, more specific information is required with regards to case-fatality, cause-fatality, and age-specific fatalities. It is also very important to understand the risk factors that might predispose people in Asia to contracting HIV/AIDS such as lifestyle, culture and religion.,

The presence of HIV/AIDS among the people of Asia affects both the government and people financially. ${ }^{6}$ Diagnostics, treatment, and healthcare comprise a major portion of medical spending done by governments. A great deal also goes to preventative measures that vary from being classified as primary to tertiary measures but all are working for the greater good of prevention and awareness. The HIV/AIDS epidemic also raises the importance of completely understanding the pathogenesis

\section{Practice Points}

- Recognizing trends in HIV/AIDS in Asia is important because it is vital to understanding the effectiveness of current approaches towards diagnosis and treatment.

- Among the risk factors that predispose people in Asia to contracting HIV/AIDS, cultural diversity carries certain social and religious stigmas associated with the disease.

- Both the incidence and case fatality rate of HIV in the Asian continent is declining with India and China having the largest number of people living with HIV.

- Financial burdens and lack of government infrastructure in the healthcare systems are largely responsible for the rapidly rising prevalence of the disease among the populations in the region along with the inaccessibility to prevention and treatment methods.

- There is a big disparity in terms of affordability and distribution of antiretroviral drugs in Asia.

and progression of an HIV infection into AIDS which of course also contributes to the financial impact it has on Asia. ${ }^{5} 6$ The ongoing search for a cure also poses a major expense. ${ }^{7}$ There is also a socioeconomic component to the impact HIV/AIDS has on Asia, due

Correspondence: Dr. Adekunle Sanyaolu, Consultant, Federal Ministry of Health, Abuja, Nigeria. Email: sanyakunle@gmail.com. 
to expensive treatments and the need of lifelong treatment hence a diagnosis of HIV is considered a life sentence of low socioeconomic status. ${ }^{7}$

There are limited ways to contract HIV infection because the only known reservoir is bodily fluids of an infected person; the virus becomes inactivated upon exposure to atmospheric air. So it is important to promote prevention of cross infection through advocating safe sex, safe practices of needle use, and honesty with partners. ${ }^{5}$, 8 . This review extensively analyzes the various current trends of HIV/AIDS in India, China, Thailand, Cambodia and Indonesia. The review also analyzes the clinical presentation, epidemiological statistics, and the financial and socioeconomic impacts of HIV/AIDS in these countries. Lastly, it explores various methods of diagnosis, treatment and prevention plans that are implemented in modern medicine with respect to HIV/AIDS.

\section{Materials and methods}

A literature search for HIV Infection/AIDS was carried out and papers were retrieved by performing searches using online electronic databases (PubMed, MedlinePlus, Mendeley, Google Scholar, ResearchGate, Global Health, and Scopus). The search ranged from the initial date for each database until 2015 and 54 results were identified. Articles were streamlined to HIV AIDS in Asia, Africa, developing countries, socioeconomic factors, epidemiology, diagnosis, prevention, treatment. Titles and abstracts of these results were reviewed and selected for inclusion based on relevance to the research question.

\section{Results and Discussion}

The key findings of the review in relation to HIV/AIDS are as follows:

\section{Source, Reservoir, and Transmission}

This virus has been found in many sources including cats, sheep, horses, and cattle. ${ }^{9}$ It originates from another virus known as the Simian Immunodeficiency Virus (SIV), which mainly affects monkeys, and is about 32,000 years old. The source of the virus crossing species is defined as the 'Hunter' theory, in which affected SIV chimpanzees were killed and eaten, and the blood entered the wounds of the hunters adapting and later progressing to what is known as the Human Immunodeficiency Virus. ${ }^{3}$

The HIV/AIDS virus causes infection by living in a 'cellular reservoir' where it can stay hidden within the blood cells for years on end. ${ }^{10}$ The genetic code is ingrained within the cells causing chronic lifelong infection. They are invisible to human body's immune system and are not sensitive to anti-retroviral drugs. ${ }^{10}$ Latent reservoirs for the disease are placed throughout the body, and organs such as the brain, lymphoid tissue, bone marrow, and the genital tract all serve as areas where the virus can remain hidden. The resting HIVinfected CD4 cells do not reproduce the virus at the time, but is established during the earliest phases of the infection. Anti-Retroviral therapy helps reduce the level of HIV in the blood to an undetectable level, but the latent reservoirs continue to survive. Once a latent infection is activated again, the cells begin to reproduce the HIV infection thus, making ART therapy ineffective. ${ }^{11}$

HIV can be spread in many ways, but they all fall under the category of body fluids. Fluids such as blood, semen, pre-seminal fluids, rectal fluids, vaginal fluids, and breast milk all carry the virus and are a source of transmission. ${ }^{12}$ Most often, it is spread by sexual contact between any type of sexual partners: male-female, female-female, and male-male relations. Anal sex is the highest-risk sexual act, followed by vaginal sex, and then multiple partner sex as listed in order of highest-tolowest in transmission rates. Another common source of transmission is the sharing of needles, syringes, rinse water, etc. used to prepare injection drugs for someone who already has the virus. ${ }^{13}$ The least common, but still accounts as a source of transmission is being born to an infected mother in which, HIV can be passed from mother to child during pregnancy, birth, or breastfeeding. ${ }^{14}$

In the South and South-East Asia regions, the biggest sources and cause of transmission of the virus is injection drug users, homosexual relationships, sex workers, and clients of sex workers who then transmit to their immediate sexual partners. ${ }^{8}$ In East Asia, the source of transmission comes from injection drug users, and prostitution. In rural areas of China, individuals who participate in blood transfusions are given unclean blood that transmits the virus. In Japan, the greatest cause of transmission of the virus is male-to-male sexual relationships, and the second greatest is being passed to infant from the womb of the mother. ${ }^{7}$ In Central Asia, the greatest cause for transmission is needle-drug use, and the increasing number of prostitutes is now a leading cause of transmission of the virus as well. ${ }^{14}$

Pathogenesis and Clinical Presentation of HIVI AIDS in Asia

Human Immunodeficiency Virus (HIV) entry into human cells and cell tropism is key to pathogenesis, the virus interacts with its V3 loop a part of glycoprotein 120 and the receptor on the host T helper cell CD4 and co-receptors CCR5 or CXCR4 on macrophage and enters by simple diffusion. Blocking of these co-receptors by inhibitors molecules prevent HIV viral entry into the host cell. ${ }^{15}$ Semen-derived enhancer of virus infection (SEVI) was thought to play a role in the ability of the virus to penetrate female vaginal epithelial barrier since the most common mode of HIV-1 transmission in female is through unprotected sexual intercourse as experiment with cell culture showed a significant enhance, but results obtained from direct application to the genital tracts of living female macaques showed that SEVI may not play a great role in male to female transmission. ${ }^{16}$

The average course of HIV infection from the initial infection to full blown AIDS is 8-10 years and this depends on the loss of CD4+ cells and the level of viremia. The higher the level of viremia the faster the disease progression from HIV to AIDS, Marcio de Oliveira Silva et al describes a case in Brazil where a man developed a full blown AIDS within 4-5 months of an acute infection, including the need for antiretroviral 
therapy. Other factors that lead to fast progression are the lifestyle, use of drugs and virulent resistant strain of HIV virus. ${ }^{1}$ HIV variants during infection can complicate therapy as quasispecies variants emerge from the initial strain as progeny viruses may express unique antigenic motifs that are different from the initial infection during the course of an HIV infection. This is a big disadvantage in the design and development of HIV vaccines. ${ }^{17}$ HIV persistence in reservoir cell as seen in CD4+ T memory stem cells during antiretroviral therapy is known to harbor a high number of viral DNA which increases the total viral load over time and causes a long-term viral persistence in infected individuals. ${ }^{18}$ Finally, T helper cell (CD4) reduction is direct cause of the HIV viral lysis while cytotoxic T cells (CD8) T lymphocytes are hyper activated by the presence of organisms, which leads to apoptosis and premature cell death. A lower immune system causes a rapid proliferation of opportunistic organisms and infections to set in overwhelmingly to invade infected individual.

\section{HIV Diagnosis}

The screening method of detecting HIV-1 and 2 infections is based on serologic testing for antibodies and/or p24 antigen by an immunoassay. The US Centers for Disease Control recommends the use of an antibody and RNA test to diagnose acute HIV infections (Figure 1). Although the sensitivity of HIV-1 antibody and p24 antigen detection has improved, there still exists a window period between the time of infection and the time of detection by serological markers. This window period is dependent on the sensitivity of the serological test used. The 4th generation p24 antigen/antibody assays may detect infection when the HIV-1 RNA concentration reaches 14,000 copies $/ \mathrm{mL}$. The limit of detection of the Aptima HIV-1 Quant Dx assay is significantly lower than 14,000 copies $/ \mathrm{mL}$ and may detect the presence of HIV-1 earlier than HIV immunoassays. ${ }^{19}$

Epidemiology \& Risk factor

Culture, along with diversity, carries certain social and religious stigma. ${ }^{20}$ These are marks of disgrace associated with a particular circumstance, quality, or person that society deems as shameful. ${ }^{20}$ This may affect individual sexual behaviors, willingness to seek testing and/or treatment, and disclosure of HIV status. HIV-related stigma may also influence government involvement in HIV / AIDS awareness, education, prevention, and protection of human rights. These factors contribute to the incidence or risk of HIV in a population. ${ }^{20}$

Both the incidence and case fatality rate of HIV in the Asian continent is declining as shown in prevalent countries in Asia i.e. China, India, Indonesia, Cambodia and Thailand (Tables $1 \& 2$ ). ${ }^{21}$ India and China had the largest number of people living with HIV (Figure 2). ${ }^{21}$

In China, HIV remains the leading cause of death among other infectious diseases. ${ }^{22}$ Out of a population of 800,000 HIV-positive people in $2011,30 \%$ were homosexuals. The remaining $70 \%$ of cases were attributed to prostitution, migrant workers, and IV drug use, in descending order. $81 \%$ of these new HIV cases were men. ${ }^{22}$ The Chinese government makes a valiant effort to assist citizens in employment, education, housing, religious guidance, social integration, and financial resources. However, due to the high value placed on family roles, secrecy is highly regarded when it comes to issues of sexual orientation. Community outreach and education are therefore very lim-

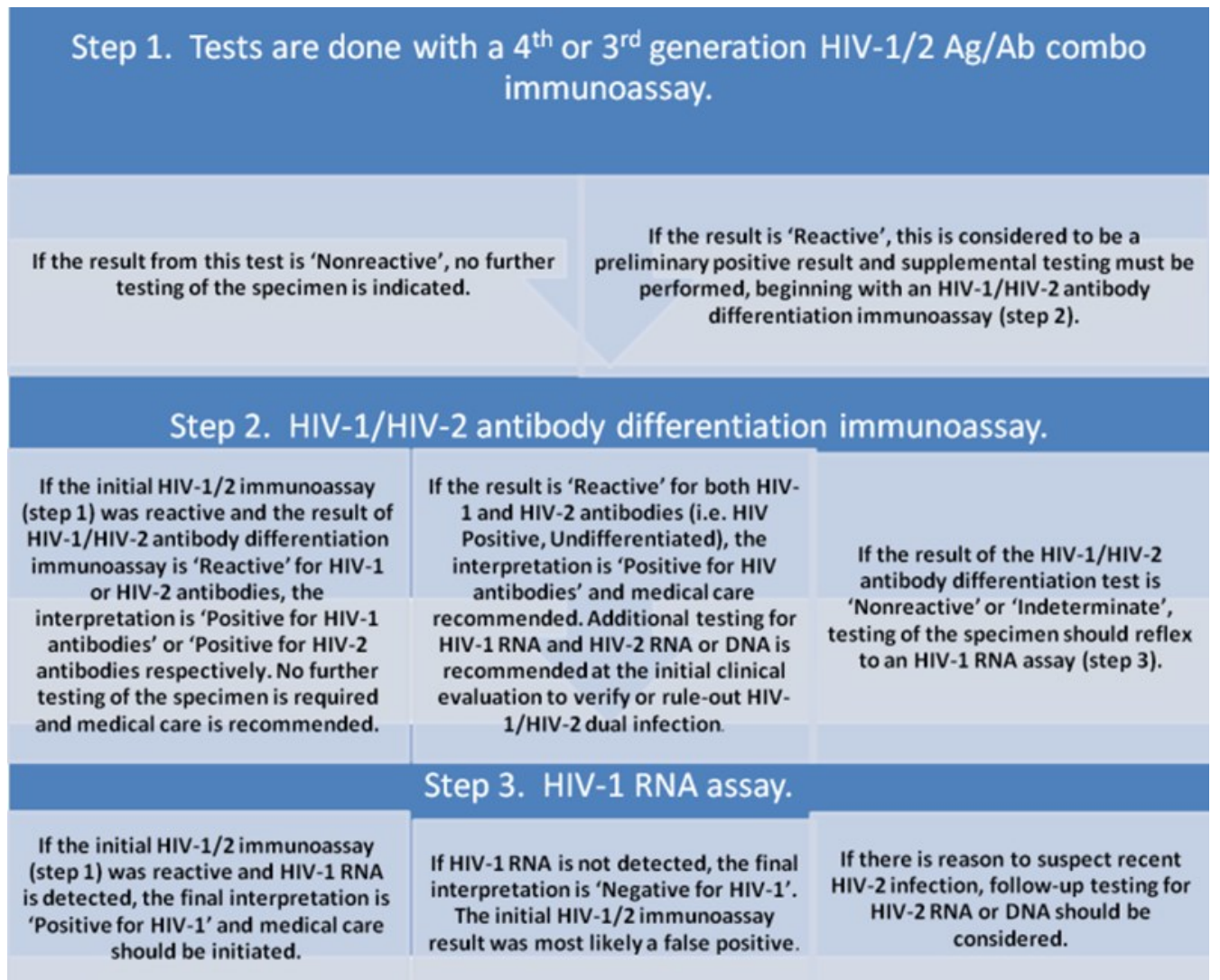

Figure 1: Diagnostic testing protocol for HIV by the Centers for Disease Control (CDC) ${ }^{12}$ 
Table 1: Comparative HIV Incidence in 5 Asian countries 2001 and $2012^{21}$

\begin{tabular}{|c|c|c|c|c|}
\hline \multirow{2}{*}{ Countries } & \multicolumn{2}{|c|}{2001} & 2012 \\
\cline { 2 - 4 } & $\begin{array}{c}\text { \# New cases } \\
\text { \# people at risk }\end{array}$ & Incidence & $\begin{array}{c}\text { \# New cases } \\
\text { \# people at risk }\end{array}$ & Incidence \\
\hline India & $\begin{array}{c}200,000 \\
1,060,000,000\end{array}$ & $0.02 \%$ & 130,000 \\
$1,200,000,000$ & $0.01 \%$ \\
\hline Thailand & $\begin{array}{c}24,000 \\
63,000,000\end{array}$ & $0.04 \%$ & 9,800 & $0.02 \%$ \\
\hline Cambodia & $\begin{array}{c}6,000 \\
12,500,000\end{array}$ & $0.05 \%$ & $1,400,000$ & $0.01 \%$ \\
\hline Indonesia & 135,000 & $14,000,000$ & $0.03 \%$ \\
\hline China & $\begin{array}{c}212,000,000 \\
1,200,000,000\end{array}$ & $0.12 \%$ & $247,000,000$ & 48,000 \\
$1,350,000,000$ & $0.004 \%$ \\
\hline
\end{tabular}

Table 2: Comparative HIV Case-Fatality in 5 Asian countries 2001 and $2012^{21}$

\begin{tabular}{|c|c|c|c|c|}
\hline \multirow[b]{2}{*}{ Countries } & \multicolumn{2}{|c|}{2001} & \multicolumn{2}{|c|}{2012} \\
\hline & $\begin{array}{c}\text { \# Deaths due to } \\
\text { HIV } \\
\text { \# Cases of HIV }\end{array}$ & Case Fatality & $\begin{array}{c}\text { \# Deaths due to HIV } \\
\text { \# Cases of HIV }\end{array}$ & Case Fatality \\
\hline India & $\begin{array}{c}123,000 \\
1,500,000 \\
\end{array}$ & $8.20 \%$ & $\begin{array}{c}132,000 \\
2,100,000\end{array}$ & $6.29 \%$ \\
\hline Thailand & $\begin{array}{c}40,000 \\
2,078,000\end{array}$ & $1.92 \%$ & $\begin{array}{c}23,000 \\
490,000\end{array}$ & $4.69 \%$ \\
\hline Cambodia & $\begin{array}{c}78,000 \\
157,000\end{array}$ & $49.68 \%$ & $\begin{array}{c}2,200 \\
75,000\end{array}$ & $2.93 \%$ \\
\hline Indonesia & $\begin{array}{c}231 \\
1,559\end{array}$ & $14.82 \%$ & $\begin{array}{c}29,000 \\
640,000\end{array}$ & $4.53 \%$ \\
\hline China & $\begin{array}{c}44,000 \\
950,000\end{array}$ & $4.63 \%$ & $\begin{array}{c}7,500 \\
1,200,000\end{array}$ & $0.63 \%$ \\
\hline
\end{tabular}

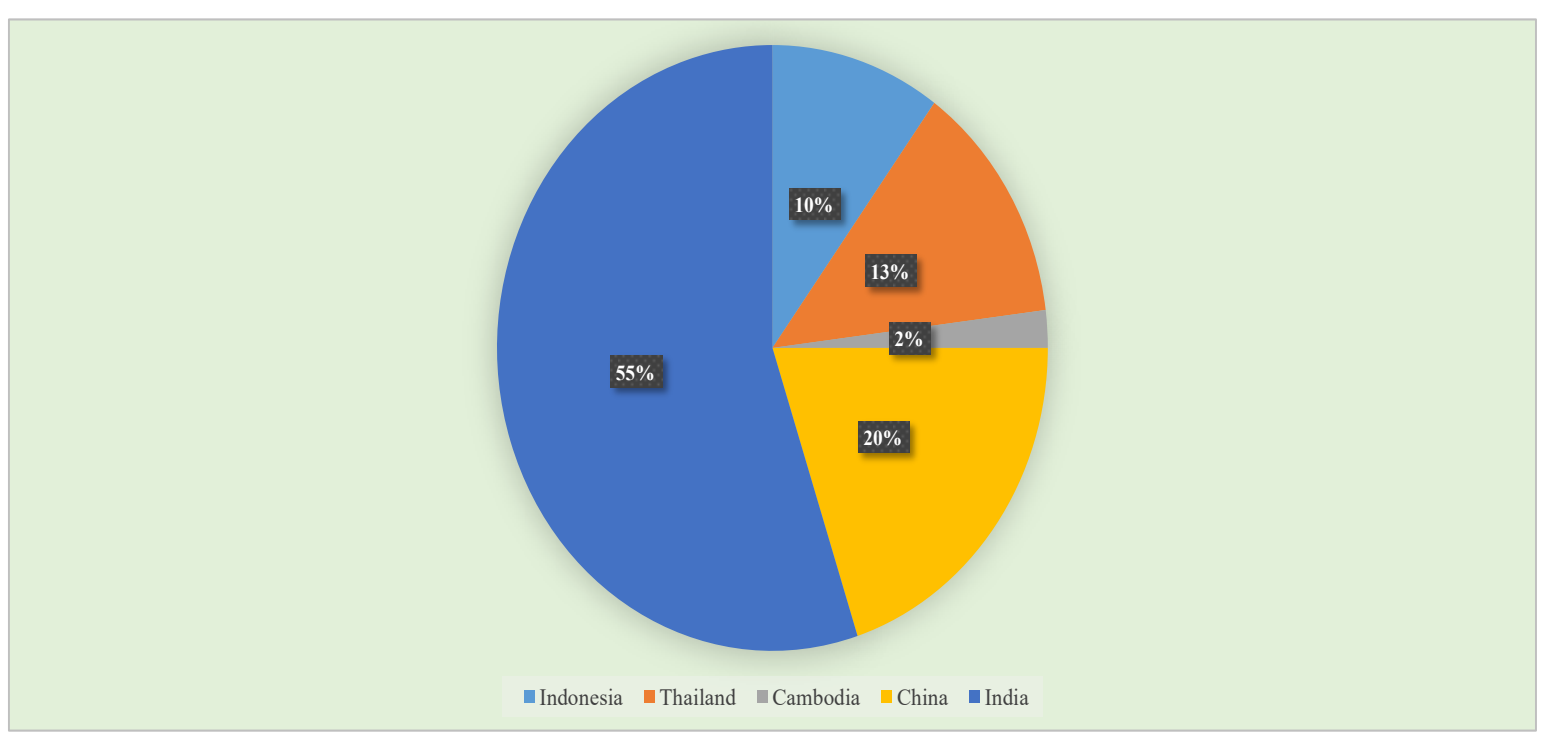

Figure 2: People infected with HIV in 5 Asian countries

ited. Up until 2001, use of public advertisement for AIDS awareness and prevention was forbidden. ${ }^{22}$

In India sexual transmission is the most prevalent source of HIV. Drug use is more common in the northeastern region of the country. ${ }^{15}$ Parent to child transmission has increased steadily since $2007 .{ }^{15}$ Stigma and discrimination are main concerns for this government.
In 1993, the government lifted an official ban on the use of television and radio for HIV information. ${ }^{16}$ In 1994, the first advertisement for condoms appeared. ${ }^{15}$ Women are significantly more likely than men to experience HIV-related discrimination within their family and community due to inferior social status. ${ }^{23}$ Husbands visit sex workers during their travels and bring HIV home 
to their wives, which then is passed on to the children. The women are then blamed for the disease and avoided within their own home. In a study of 40 men visiting STD clinics, 53\% admitted to having multiple sexual encounters while working away from home. It is estimated that $43 \%$ of sex workers in Mumbai are infected with HIV. ${ }^{15}$ Human trafficking is also an issue in India contributing to a marked increase in HIV among teenage girls and even young boys. ${ }^{24}$ Local churches often give their support to victims of HIV in the form of prayers, food, and shelter. Studies show that most HIV-infected people in this country are religious. ${ }^{24}$

There is a decrease in HIV among female sex workers with a recent study showing $29 \%$ in brothel-based sex workers and $15 \%$ in direct sex workers. ${ }^{25}$ This could be due to the recent increase in condom use. The National Center for HIV/AIDS, Dermatology, and STD's in Phnom Penh has stepped up to the plate with regards to prevention, monitoring, and education. There does not seem to be the same HIV-related stigma in Cambodia that exists in other countries. ${ }^{25}$

In July 2012, The Guardian headlined an article about Indonesia's condom campaign to fight AIDS and how it had been greatly criticized by religious groups. ${ }^{26}$ Conservative Muslims, according to The Guardian, were accusing the government of promoting promiscuity. ${ }^{26}$ Social stigma and sexual taboos hinder Indonesia's fight against AIDS and HIV. Although prevalence is only $0.2 \%$ in a total population of 238 million people, new cases of HIV went from 7,195 in 2006 to 21,031 in 2011. 25,26 Seventy five percent $(75 \%)$ of these new HIV infections occur in heterosexuals, $16 \%$ in intravenous drug users, and $2.5 \%$ in homosexuals. Religion in Indonesia has become more conservative resulting in the closure of some red-light districts and churches involvement in promoting safe sex..$^{25,26}$ However, unregulated sex work is on the rise and condom promotion is targeted at married couples due to strict beliefs regarding no sex before marriage. Some leaders are reluctant to become involved in fear that HIV education for their community might go against religion based tradition on matters such as sex before marriage. $^{25,26}$

Nightlife, tourism, entertainment, and the sex industry seem to be the matter for Thailand. Unsafe sex accounts for about $90 \%$ of HIV in Phuket alone. ${ }^{26}$ In August of 2008 , the case fatality rate for Phuket was $27.4 \%$. Hospitals are prepared to deal with the rise in HIV/AIDS as it has become more of a norm. Religious beliefs do not hinder treatment as seen in other areas of Asia. In this society, sex is promoted highly and prostitution is in the open. $^{26}$ Gay pride events are held almost weekly in Phuket and many accommodations are provided for the gay community such as the Phuket Gay Homestay. However, the prevalence of HIV seemed to be evenly distributed among the population without sexual preference. $^{26}$

\section{Financial \& Socioeconomic Impact}

The vast majority of people in developing countries who are living with HIV/AIDS are unable to access life-saving treatment for HIV infection and other related opportunistic infections. For many of these countries, the U.S. is the Global Fund's largest contributor. ${ }^{27}$ The US government first provided funding to address the global
HIV epidemic in 1986, and funding has increased significantly over time, particularly in the prior decade. $^{27}$

Many of the drugs for the treatment of HIV/AIDS are out of the price bracket for majority of the people except a small minority living with HIV/ AIDS in developing countries. While the introduction of antiretroviral therapies has benefited persons living with HIV/AIDS in developed countries these treatments remain largely inaccessible to people in developing countries. ${ }^{6}$

The financial impact on many of the Asian governments is a great consideration when looking to finance the medical costs of HIV/AIDS. One of the obvious reasons for difficulties faced by these countries is the cost of the medications and the lack of government support to pay them. ${ }^{6}$ Most of these Asian countries are still largely developing and don't even have the ability to provide a proper living structure for its citizens. So when basic needs are not met like food, water, and shelter; medical ailments take a backseat. Despite the changes in basic and social need in society, there is also the ongoing battle of the patents on the drugs. After manufacturers make these drugs, they patent and monopolize the sales on them. ${ }^{6}$

\section{Prevention of Cross Infection}

As stated before, the Human Immunodeficiency Virus (HIV) is an opportunistic RNA retrovirus that attacks the immune system's $\mathrm{T}$ helper cells and compromises the body's ability to fight off pathogens and foreign entities. HIV results in the decline of CD4+ T-helper cells, and this, in turn, causes the body to be more susceptible to becoming infected by pathogens, such as Pneumocystis jiroveci, which would not normally infect nonimmuno-compromised individuals. ${ }^{28}$ Over the past 30 years, there have been various methods for identifying HIV, as well as, many drugs that treat and manage the virus. ${ }^{28-30}$ Protocols designed to treat HIV patients continue to evolve every day allowing HIV-positive patients to live a longer and less debilitating life. Nevertheless, prevention of HIV cross-infection is an extremely important factor that can reduce the incidence of HIV infection across populations and multiple geographic areas. At the same time, prevention of HIV cross-infection can allow people to be better prepared and reduce the burden on health care. An important point is to clarify that prevention of HIV cross-infection is not the same as the management of HIV. Prevention of HIV cross-infection can be effectively conveyed through educational means. The use of media, advertisement outlets, and the patient-physician relationship has been proven to be most effective in the preventions of HIV crossinfection. ${ }^{29,30}$ Research has shown that when government health organizations and health enthusiasts use media to educate people about certain diseases as in this case HIV, a considerable amount of people have responded positively; not only by testing themselves for HIV but also by being better prepared and taking cautionary steps before engaging in sexual intercourse. ${ }^{18,31}$ Moreover, when a physician explains the dangers of engaging in 
unprotected sex with random partners, people tend to practice safer sex. ${ }^{32}$

To be effective in educating people about the severity of HIV and the potential health risks associated with this virus, the aforementioned entities should adhere to the following methods of prevention: Primordial prevention, Primary Prevention, Secondary Prevention, and Tertiary Prevention. ${ }^{33}$ The prevention criteria mentioned in the latter half of the paper is relevant to countries including China, Cambodia, India, Thailand, and Indonesia respectively.

\section{Primordial Prevention}

Primordial prevention is the first line of defense aimed at preventing HIV spread prior to any contact with the virus. Moreover, primordial prevention is a broad environmental prevention method that addresses social, economic, cultural, and behavioral patterns that might increase the chance of transmission of the virus. ${ }^{34,35}$ Making educational safe sex brochures available at physician's offices or implementing safe sex education programs in schools, universities, and community centers, while at the same time improving community sanitation are prime examples of primordial prevention. Education regarding the high risks associated with polygamous relationships, promiscuity and the practice of unsafe sex can also be a way to introduce conscious and safe sexual behavior, especially in young and inexperienced people. ${ }^{36}$ Additionally, the improvement in sanitation in communities in conjunction with the practice of safe sex and the use of condoms tends to yield a greater number of health-conscious individuals. It is important to also mention that many patients respond positively to physician avocation for the use of condoms and safe sex during coitus. ${ }^{17,37}$

\section{Primary Prevention}

Primary prevention employs ways to positively change behavior that can also amplify resistance when exposed to the virus. Good examples of primary prevention are put in practice when physicians screen for STDs during urine and blood testing and hand out free condoms at their clinics. Also, when condoms are made available for sale at public places like airports, bars, and restaurants, and when colleges and universities give away condoms to both male and female students along with a brief explanation as to why condoms can reduce the likelihood of transmission of HIV and other sexually transmitted diseases. ${ }^{38-40}$ It is important to note that the transmission of HIV is not exclusive to sexual intercourse. Patients that undergo surgery, blood transfusions or dental procedures could be exposed to HIV if proper testing and sanitation protocols are not followed. ${ }^{40}$ Moreover, it is a clinician's responsibility to ensure that only sterile materials come in contact with patients and that surgical materials are discarded or sterilized appropriately after each medical procedure in order to eradicate the virus and prevent transmission. ${ }^{41,42}$

\section{Secondary Prevention}

Secondary prevention in the context of HIV transmission is a form of management rather than prevention. This is because HIV is not a curable disease and current treatment, based on the use of antiretroviral drugs, will not eradicate the virus from a patient's body, but will rather limit the severity of the immunocompromise. In other words, the antiretroviral drugs, through various pharmacological mechanisms of action will only prevent and/or slow the progression of adverse complications. ${ }^{1}$ Secondary prevention would identify the presence of HIV in a patient's blood serum and would also incorporate the implementation of appropriate treatment regimens prior to the manifestation of symptoms or complicated infections. ${ }^{43,44}$ The treatment's aim is to manage HIV and to maintain patient vitality. New research is emerging every year, thereby allowing researchers to synthesize new drugs that can halt the replication and transfer of HIV viral RNA from cell to cell. The development of protease inhibitors, such as $\mathrm{Ri}$ tonavir, and reverse transcriptase inhibitors, such as Zidovudine, have been and continue to be the mainstay of HIV Highly Active Antiretroviral Therapy (HAART) for the past three decades. ${ }^{45-47}$ However, over the past few years, the emergence of CCR5 receptor antagonists, such as Maraviroc, have slowed replication of the virus and decelerated the decline in CD4+ T cell count, which at the same time, decreases the incidence of opportunistic infections, such as Pneumocystis jiroveci, Cytomegalovirus, and Kaposi's Sarcoma. ${ }^{2,45-47}$ This is a large leap into effectively tackling HIV within a short period of time.

Once HIV is contracted, it is imperative that the patient communicates his or her sexual and social history to their physician. This patient-doctor relationship must be established through open communication and empathetic concern from the physician without any bias or moral reprimand imposed on the patient. Additionally, it is extremely important that the physician continuously monitors CD4+ $\mathrm{T}$ cell levels every month to determine the effectiveness of treatment, as well as prevent further decline of $\mathrm{CD} 4+\mathrm{T}$ cells aiming at reducing the risk of complicated infections. Once CD4 $+\mathrm{T}$ cells levels fall below approximately 350 cells $/ \mathrm{mm}^{3}$, then that is when antiretroviral medication must be prescribed at an appropriate dosage. $^{48}$

\section{Tertiary Prevention}

Tertiary prevention is the final stage of management as well as a way of prevention. This method aims at improving the quality of life of people infected with HIV. This is done by maintaining proper treatment regimens and by preventing further loss of CD4 $+\mathrm{T}$ cells. Tertiary prevention seeks to slow the progression of the HIV disease to full-blown AIDS, the point where the disease can become deadly. ${ }^{49}$ For example, HIV-positive patients that has a CD4+ T cell count lower than 350 cells/ $\mathrm{mm}^{3}$ falls under AIDS category and are at high risk of developing infections that are not commonly seen in the general population. ${ }^{50}$ The goal of HIV HAART therapy is to lower HIV viral load to about 40-75 copies of $\mathrm{RNA} / \mathrm{mL}$ and to allow HIV patients to live symptomfree for, in some cases, decades at a time. ${ }^{19}$ Unfortunately, once symptoms and infections have started, this may tarnish the patient's confidence and instill a feeling of hopelessness. Although palliative care may be the only means for a patient with AIDS, it is highly recommended for physicians to be empathetic to HIV positive patients who may not adequately respond to HAART therapy or may be in the late stages of AIDS. It is recommended that physicians refer these patients to AIDS support groups where patients can discuss their illness with other people who have been affected by the same illness and can share ideas on how they can best manage their conditions. This tends to make affected patients 
feel more like they belong in the society, accept their condition, and follow appropriate treatment regimens. ${ }^{51,52} \mathrm{HIV}$ is a serious illness that has had and continues to have a devastating impact on human health. It is critical that the general public is made aware of preventive methods that can aid in the prevention of HIV cross-infection.

\section{Treatment}

There is a big disparity in terms of affordability and distribution of antiretroviral drugs in Asia. In 2011, antiretroviral treatment was only accessed by $47 \%$ of people that needed these drugs in South and South-East Asia, and $18 \%$ in East Asia. ${ }^{32}$ Thailand and Cambodia had an accessed coverage of $71 \%$ and $95 \%$ percent and Malaysia and the Philippines had 37\% and 51\% respectively. ${ }^{32}$ High cost of antiretroviral drugs both first and second-line drugs were unaffordable by many governments which puts a huge constraint on treatment. Currently cheaper HIV drugs are now produced by a number of pharmaceutical manufacturers in Asia with the increasing availability of lower-cost branded ARVs, it will be easier for governments to obtain and distribute the drugs. ${ }^{32}$ Unfortunately, even where drugs are available, the poor state of healthcare in many Asian countries, particularly shortage of trained doctors and other health personnel, is hindering governments' abilities to organize life-long treatment programs for millions of people living with HIV and AIDS. ${ }^{32}$

For adults and adolescents, it is recommended to start on a first line therapy of two nucleoside reversetranscriptase inhibitors (NRTIs) plus a non-nucleoside reverse-transcriptase inhibitor (NNRTI). ${ }^{51}$ The favored recommendation is a fixed-dose combination (just one pill) of TDF - Tenofovir, 3TC - Lamivudine or FTC Emtricitabine and EFV - Efavirenz. ${ }^{51}$ At the beginning of treatment, the first line therapy is initiated. If after a while HIV becomes resistant to this combination, or if the side effect becomes very serious, then a change to second-line therapy is recommended. ${ }^{51}$ Second line therapy as recommended by the WHO include two NRTIs and a ritonavir-boosted protease inhibitor (PI). ${ }^{51}$ Nucleoside/Nucleotide Reverse Transcriptase Inhibitors NRTIs, nucleoside analogues, interfere with the action of an HIV reverse transcriptase, which the virus needs to make new copies of itself. Non-Nucleoside Reverse Transcriptase Inhibitors NNRTIs, also stop HIV from replicating within cells by inhibiting the reverse transcriptase protein. Protease Inhibitors (PIs) inhibit protease, a protein involved in HIV replication process. Fusion or Entry Inhibitors prevent HIV from binding to or entering human immune cells (CD4). Integrase Inhibitors interfere with the integrase enzyme, which HIV needs to insert its genetic material into human cells. NRTIs and NNRTIs are available in most countries. Fusion /entry inhibitors and integrase inhibitors are usually only available in resource-rich countries. Protease inhibitors are generally less suitable for starting treatment in resource-limited settings due to the cost, number of pills which need to be taken, and the side effects caused by protease drugs. ${ }^{51,52}$

\section{Conclusion}

As discussed, HIV/AIDS infection is an ongoing issue in Asia as well as the rest of the world. However, the trends show a decrease in both incidence and case fatality. This could be due to many reasons, but the most likely explanation is that many factors are working together in a positive manner and decreasing the numbers of new infections. An example of these factors would be better screening methods, promoting awareness among people and education on safer practices. Although HIV/AIDS still can't be cured in individuals, its impact on the immune system can be delayed via antiretroviral treatment. New research will enable us to treat infections and prevent progression in a more efficient manner that will hopefully reduce the burdens on healthcare not only in these countries but the rest of the world.

\section{Competing interest}

The authors declare that they have no competing interests.

\section{Acknowledgement}

We hereby acknowledge the contributions of the following medical students at Saint James School of Medicine, Anguilla to this project: Ivan Escudero, Tanzina Khan, Shawn Sewak, Tashfeen Tariq, and Rabiya Younas.

\section{References}

1. Anglemyer A, Horvath T, Rutherford G. Antiretroviral therapy for prevention of $\mathrm{HIV}$ transmission in HIV-discordant couples. JAMA 2013; 310(15):1619-20.

2. De Clercq E. Emerging anti-HIV drugs. Expert Opin Emerg Drugs 2005;10(2):241-74.

3. Detels R. HIV/AIDS in Asia: Introduction. AIDS Educ Prev 2004 16(1):1-6.

4. Jerez SE. The Vulnerability of Southeast Asian Ethnic Minorities to HIV/AIDS. Undercurrent $J$ 2004;10(3):29.

5. UNAIDS. Regional Fact Sheet 2012: Asia and the Pacific - Mixed progress in reducing new HIV infections and AIDS-related deaths [Internet]. UNAIDS; $2012 . \quad \underline{\text { http:// }}$ files.unaids.org/en/media/unaids/contentassets/ documents/epidemiology/2012/ gr2012/2012 FS regional asia pacific en.pdf (accessed Dec 2017)

6. Interagency Coalition on AIDS and Development. Civil Society Perspective on Canada's Global Engagement on HIV and AIDS.. Ottawa: Interagency Coalition on AIDS and Development, 2007.

7. Hardon A, Desclaux A, Egrot M, Simon E, Micollier E, Kyakuwa M. Alternative medicines for AIDS in resource-poor settings: insights from exploratory anthropological studies in Asia and Africa. J. Ethno-biology and Ethno-medicine. 2008; 4(1):16.

8. Piper N, Yeoh BS. Introduction to special issue: Meeting the challenges of HIV/AIDS in Southeast and East Asia. A sia Pacific Viewpoint 2005; 46(1):1-5.

9. Sadik N. Forced migration and HIV/AIDS in Asia: some observations. Forced Migration Review. 2010 Oct 1:4. 
10. Sharma M, Chatterjee A. Partnering with law enforcement to deliver good public health: the experience of the HIV/AIDS Asia regional program. Harm Reduc. J. 2012; 9(1):24.

11. Tran BX, Nguyen LH, Ohinmaa A, Maher RM, Nong VM, Latkin CA. Longitudinal and cross sectional assessments of health utility in adults with HIV/AIDS: a systematic review and metaanalysis. BMC Health Services Research. 2015; 15(1):7.

12. Beyrer C. Accelerating and disseminating across Asia. Washington Quart 2001; 24(1):211-25.

13. Kent SJ, Cooper DA, Vun MC, Shao Y, Zhang L, Ganguly N, Bela B, Tamashiro H, Ditangco R, Rerks-Ngarm S, Pitisuttithum P. AIDS vaccine for Asia Network (AVAN): expanding the regional role in developing HIV vaccines. PLoS Med. 2010; 7(9):e1000331.

14. Simonet D. The AIDS Epidemic and Migrants in South Asia and South-East Asia. Int Migration 2004; 42(5):35-67.

15. Tarakeshwar N. AIDS \& Hinduism in India [Internet]. Religion, Disease, Healing, India Belief net - Page 2. Beliefnet, Inc. and/or its licensors; Available from: http:// www.beliefnet.com/faiths/2005/08/aidshinduism-in-india.aspx? $\mathrm{p=2 \# kDReyDr7D4LTRsqE.99}$ (accessed Dec 2017).

16. Statement Containing Brief Activities of the Department of AIDS Control in 2013. 1st Ed. New Delhi: Department of AIDS Control Ministry of Health \& Family Welfare Government of India, 2017.

17. Baelden D, Van Audenhove L, Vergnani $\mathrm{T}$. Using new technologies for stimulating interpersonal communication on HIV and AIDS. Telematics and Informatics. 2012; 29(2):166-76.

18. Bertrand JT, Anhang R. The effectiveness of mass media in changing HIV/AIDS-related behaviour among young people in developing countries. Technical Report Series-World Health Organ. 2006; 938:205.

19. Bower M, Fox P, Fife K, Gill J, Nelson M, Gazzard B. Highly active anti-retroviral therapy (HAART) prolongs time to treatment failure in Kaposi's sarcoma. AIDS. 1999; 13(15):2105-11.

20. Cameron S, Wilson J, Hows J, Pascal R, Todd-Gher J, Tremlett L, Stevens A, Godwin J. People Living with HIV Stigma Index: Asia Pacific regional analysis, 2011.

21. UNAIDS. HIV in Asia and the Pacific. Joint United Nations Programme on HIV/AIDS (UNAIDS). UNAIDS Report 2013. Geneva: UNAIDS. 2013.

22. Centers for Disease Control and Prevention (CDC. Racial/ethnic disparities in diagnoses of HIV/AIDS--33 states, 2001-2004. MMWR 2006; 55(5):121.

23. Khawaja ZA, Gibney L, Ahmed AJ, Vermund SH. HIV/AIDS and its risk factors in Pakistan. AIDS. 1997; 11(7):843-8.
24. Sopheab H, Fylkesnes K, Vun MC, O'Farrell N. HIV-related risk behaviors in Cambodia and effects of mobility. J Acquir Immune Defic Syndr 2006; 41(1):81-6.

25. Sin, Sex and Science: The HIV/AIDS Crisis. American-European Healthcare since 1800. 2014. http://history.msu.edu/hst425/resources/ online-essays/sin-sex-and-science-the-hivaidscrisis/ (accessed Dec 2017)

26. The Guardian. Indonesia's condom campaign to fight Aids criticised by religious groups [Internet]. The Guardian. Guardian News and Media; 2012. Available from: http:// www.theguardian.com/global-

development/2012/jul/24/indonesia-condom-aids -religious-groups (accessed Dec 2017)

27. U.S. Funding for Global Health: The President's FY 2014 Budget Request. The Henry J. Kaiser Family Foundation. 2013. Available from: http:// kff.org/global-health-policy/fact-sheet/u-sfunding-for-global-health-the-presidents-fy-2014 -budget-request/ (accesed Dec 2017)

28. Dragic T, Litwin V, Allaway GP. HIV-1 entry into CD4 plus cells is mediated by the chemokine receptor CC-CKR-5. Nature 1996; 381(6584):667.

29. Vidanapathirana, J., Abramson, M. J., Forbes, A., \& Fairley, C. (2005). Mass media interventions for promoting HIV testing (Review). Cochrane Database of Syst Rev 2005;3:1-38.

30. W. Vaughan, Everett M. Rogers, Arvind Singhal, Ramadhan M. Swalehe P. Entertainmenteducation and HIV/AIDS prevention: A field experiment in Tanzania. J. Health Comm. 2000; 5(sup1):81-100.

31. Farr AC, Witte K, Jarato K, Menard T. The effectiveness of media use in health education: Evaluation of an HIV/AIDS radio campaign in Ethiopia. J. Health Comm. 2005; 10(3):225-35.

32. Chapman S. Stopping AIDS: AIDS/HIV public education and the mass media in Europe. BMJ. 1997; 315(7114):1027-8.

33. Joffe H. AIDS research and prevention: a social representational approach. British J. Med Psycho. 1996; 69(3):169-90.

34. Ford N, Koetsawang S. A pragmatic intervention to promote condom use by female sex workers in Thailand. Bull.World Health Organ. 1999; 77 (11):888.

35. Lorway R, Reza-Paul S, Pasha A. On becoming a male sex worker in Mysore: Sexual subjectivity, "empowerment," and community-based HIV prevention research. Med Anthropol Q2009; 23 (2):142-60.

36. Spring B, Moller AC, Coons MJ. Multiple health behaviours: overview and implications. J. Public Health 2012; 34(suppl 1):i3-10.

37. Patton C. Last served? Gendering the HIV pandemic. London: Taylor \& Francis, 1994.

38. Hyde ST. Selling sex and sidestepping the state: Prostitutes, condoms, and HIV/AIDS prevention 
in southwest China. East Asia 2000; 18(4):10836.

39. Roper WL, Peterson HB, Curran JW. Commentary: condoms and HIV/STD prevention - clarifying the message. Am J. Public Health. 1993; 83(4):501-3.

40. Weller SC, Davis-Beaty K. Condom effectiveness in reducing heterosexual HIV transmission. Cochrane Database Syst Rev 2001; (3):CD003255.

41. Hernigou P, Gras G, Marinello G, Dormont D. Influence of irradiation on the risk of transmission of HIV in bone grafts obtained from appropriately screened donors and followed by radiation sterilization. Cell Tissue Banking 2000; 1(4):279-89.

42. Miekka SI, Burgess W, Drohan WN, Griko Y, MacPhee MJ, Mann DM, inventors; Clearant, Inc., assignee. Methods for sterilizing biological materials. United States patent US 6946098, 2005.

43. Downs AM, De Vincenzi I. Probability of heterosexual transmission of HIV: relationship to the number of unprotected sexual contacts. $J$ Acquir Immune Defic Syndr . 1996; 11(4):38895.

44. Strathdee SA, Sherman SG. The role of sexual transmission of HIV infection among injection and non-injection drug users. J. Urban Health 2003; 80:iii7-14.

45. Droste JA, Verweij-van Wissen CP, Burger DM. Simultaneous determination of the HIV drugs indinavir, amprenavir, saquinavir, ritonavir, lopinavir, nelfinavir, the nelfinavir hydroxymetabolite M8, and nevirapine in human plasma by reversed-phase high-performance liquid chromatography. Therapeutic Drug Monitoring. 2003; 25(3):393-9.
46. Rouzioux C, Hubert JB, Burgard M, Deveau C, Goujard C, Bary M, Séréni D, Viard JP, Delfraissy JF, Meyer L. Early levels of HIV-1 DNA in peripheral blood mononuclear cells are predictive of disease progression independently of HIV-1 RNA levels and CD4+ T cell counts. $J$. Infect. Dis 2005; 192(1):46-55.

47. Worm SW, Sabin C, Weber R, Reiss P, El-Sadr W, Dabis F, De Wit S, Law M, Monforte AD, Friis-Møller N, Kirk O. Risk of myocardial infarction in patients with HIV infection exposed to specific individual antiretroviral drugs from the 3 major drug classes: the data collection on adverse events of anti-HIV drugs (D: A: D) study. J. Infect. Dis 2010; 201(3):318-30.

48. Viard JP, Burgard M, Hubert JB, Aaron L, Rabian C, Pertuiset N, Lourenço M, Rothschild C, Rouzioux C. Impact of 5 years of maximally successful highly active antiretroviral therapy on CD4 cell count and HIV-1 DNA level. AIDS. 2004; 18(1):45-9.

49. Kumarasamy N, Mahajan AP, Flanigan TP, Hemalatha R, Mayer KH, Carpenter CC, Thyagarajan SP, Solomon S. Total lymphocyte count (TLC) is a useful tool for the timing of opportunistic infection prophylaxis in India and other resource-constrained countries. J Acquir Immune Defic Syndr 2002; 31(4):378-83.

50. Strategies for Management of Antiretroviral Therapy (SMART) Study Group. CD4+ countguided interruption of antiretroviral treatment. NEMJ 2006; 2006(355):2283-96.

51. Coates TJ, Richter L, Caceres C. Behavioural strategies to reduce HIV transmission: how to make them work better. Lancet. 2008; 372 (9639):669-84.

52. Gonzalez JS, Penedo FJ, Antoni MH, Durán RE, McPherson-Baker S, Ironson G, Isabel Fernandez M, Klimas NG, Fletcher MA, Schneiderman N. Social support, positive states of mind, and HIV treatment adherence in men and women living with HIV/AIDS. Health Psychol 2004; 23(4):413. 